Article

\title{
The Winds and the Waves That Carved Out Today's Coastal Landscape of Sines (Portugal)
}

\author{
Jacinta Fernandes ${ }^{1, *}$, Joana Bizarro ${ }^{2}$, Nuno de Santos Loureiro ${ }^{1(1)}$ and Carlos B. Santos ${ }^{3}(\mathbb{C}$ \\ 1 Faculty of Science and Technology, University of the Algarve, 8005-139 Faro, Portugal; nlourei@ualg.pt \\ 2 APS—Ports of Sines and the Algarve Authority, S. A., 7521-953 Sines, Portugal; joana_bizarro@hotmail.com \\ 3 Institute of Engineering, University of the Algarve, 8005-139 Faro, Portugal; cbraganca@ualg.pt \\ * Correspondence: mfernan@ualg.pt
}

Received: 30 June 2020; Accepted: 30 September 2020; Published: 15 October 2020

\begin{abstract}
The Atlantic maritime winds and waves, as natural forces, shaped the physiography of Sines, a peculiar rocky cliff cape at the western Portuguese coast, as well as cultural processes have shaped its spatial arrangement since ancient times. Despite its small size, Sines port has always been an important maritime trade corner. In the 1970s, winds and waves of modernity reached the Sines coast with an imposing industrial-port complex. We present the history of Sines cape focusing on its landscape dynamics. The patch-corridor-matrix model allowed us to describe the mosaic transformation of such a unique landscape. Spatial information was gathered mostly from historical maps processed with digital tools. A time series of thematic maps (landscape mosaic pattern) was obtained, covering more than 120 years. Current results emphasize that this landscape underwent relevant transformations related to human activities since former times, although disturbance and fragmentation of the landscape were strongly intensified after the arrival of the post-modern wave of the industrial culture. The present study provides a contribution to the history of the Portuguese and Mediterranean coastal landscapes; and results could be used to support decision making in sustainable management of this territory.
\end{abstract}

Keywords: landscape pattern; patch-corridor-matrix model; landscape dynamics; coastal landscape; Sines cape

\section{Introduction}

Landscapes are dynamic entities resulting from complex interactions between human and non-human forces. Consequently, landscapes of the present are part of the human legacy and each landscape has its own history (Antrop 2000). Because landscapes changed very fast over the last century, land management and landscape planning have become of growing importance and are major issues nowadays (Stäuble et al. 2008). When conducting sustainable land management, historical perspective is needed to understand the landscape as both a biophysical and a sociocultural dynamic reality (Domon and Bouchard 2007). In fact, space is continuously shaped by natural and anthropogenic processes and the analysis of temporal changes in a landscape structure is crucial to understand its history and function (Forman 1995a). Such an understanding of the landscape dynamics requires insights into the general pattern of landscape changes and its related driving forces (Bürgi et al. 2010).

Since the beginning, landscape has been a man-made artefact and it still is explained as a cultural construct. Moreover, the term cultural landscape has been used to denominate landscapes designed or intentionally created by humans that people have settled in and modified over time (Taylor and Lennon 2011). Cultural landscapes have often been referred to as agricultural or rural landscapes that occur between the natural and the urban landscapes (Jones 2003). Cultural landscapes are at the interface between nature and culture, tangible and intangible heritage, biological and cultural 
diversity, and represent a close interrelationship between people, events, and places through time (Taylor 2012). The term cultural landscape goes back to the end of 19th century, and since the 1960s it became widely used by several disciplines (Jones 2003; Wu 2010). In the early 1990s, cultural landscapes were recognized and protected by a legal instrument-The World Heritage Convention.

In Europe, from the Renaissance until the 19th century, traditional agricultural landscape became a mixed agricultural system, integrating forest, pastures, and rough grazing lands (Vos and Meekes 1999). Since the 19th century and particularly during the 20th century, anthropogenic activities have resulted in a rapid and drastic change in landscape mosaics that not only considerably impacted its ecological function but also damaged the historical cultural landscapes. Since economic, social, and political factors have played major roles in the continual development of the landscape structure, there is an increasing need for planning and management strategies that combine the preservation of biodiversity (and landscape diversity) with sustainable use of land resources. This knowledge allows to identify areas of conflict (Mojses and Petrovič 2013), mainly between nature and landscape conservation on one hand, and economic and sociocultural uses on the other hand. Among cultural landscapes, coastal landscapes draw special attention from the landscape ecologist because they have been affected by humans since ancient times, and it is well known that they are under high pressure at present times. Coastal landscapes are abundant in Mediterranean countries. Their cultural and ecological relevance makes it necessary to increase the knowledge about these types of landscapes (Cullotta and Barbera 2011). The fact that the Mediterranean coast has been significantly colonized and exploited by man for several millennia, and therefore exhibits a modified (disturbed) state (Bellini et al. 2008), makes it a particularly interesting object for landscape history studies.

The influence of spatial and temporal landscape patterns has long been hypothesized to affect many ecological phenomena (Cullinan and Thomas 1992). Today it is generally assumed that the widespread alteration, destruction, and/or fragmentation of natural ecosystems by human-related land uses represents a great threat to the world's biodiversity (Brudvig et al. 2017). Most landscapes have been strongly influenced by anthropogenic uses and their resulting landscape mosaic is a mixture of natural and complex human-managed patches (Mojses and Petrovič 2013), where a specific spatial composition and the configuration of elements forms a pattern, a spatial arrangement of the landscape structural elements (Forman 1995a). Because landscape patterns affect physical, chemical, and biological processes and the spatial distribution and diffusion of ecological disturbances in heterogeneous landscapes (Wu et al. 2012), the study and management of such dynamics are major topics in landscape ecology. Since it is difficult to study ecological processes directly, landscape ecologists often investigate landscape processes and functions by analyzing spatial and temporal patterns (Cullinan and Thomas 1992). Several systems and methods for landscape identification and classification have been proposed to conceptualize the variety of contemporary landscapes. Biophysical landscape approaches, which rely strongly on the analysis of the presence and/or abundance of landscape elements and its properties, are rooted in natural sciences and are adopted by physical geographers and landscape ecologists alike (Simensen et al. 2018). Quantitative methods, such as landscape metrics that quantify landscape patterns, have been used to study landscape function, landscape changes, and ecological related management (Wu et al. 2012). Fundamental structural types of landscape elements-patches, corridors, and matrix - differ among them in the distribution of species, energy and materials (Forman and Godron 1986). Landscape pattern analysis relies mostly on the traditional and well-established patch-corridor-matrix paradigm (Wu et al. 2012). This model has been applied for the study of aquatic landscapes (e.g., Dominik et al. 2012; Kracker 1997), urban landscapes (e.g., Aminzadeh and Khansefid 2010), and agricultural landscapes (e.g., Luo et al. 2017). Mediterranean landscapes have also been studied under this paradigm (Doorn and Correia 2007; Uzun and Gültekin 2011; Zaccarelli et al. 2008).

Sines is a cape located on the Southwest of Europe, in a peculiar geologic sector which makes a distinct contrast with the southwest Portuguese coastal area (Pombo et al. 2004). In spite of its location in the Atlantic Portuguese coast, climatic characteristics and vegetation are typically Mediterranean. Human occupation of this ecologically peculiar and sensible place always had a direct relationship 
with the sea and its resources. Sines has been an important maritime trade corner since ancient times and it is the birthplace of Vasco da Gama, the famous navigator. He discovered the sea route to India, often referred to as a starting point of globalization (Rodrigues and Devezas 2009). The Portuguese geographer Orlando Ribeiro mentions that, since early human history, the intersection points of maritime routes were "privileged places for the exchange of products and the coexistence of Men. The leaven of urban life has often been the port, which in the Mediterranean city retains an exceptional importance" (Ribeiro 1945, p. 34). Protected from prevailing northerly winds, the deep waters of the Sines bay are a natural shelter for navigation endowed with an excellent geostrategic position (APS 2004). Industrial development reached most of the important European maritime corners early in the 20th century and transformed them into ports of polluted waters, in the vicinity of noisy towns and hard urban-industrial landscapes. Sines remained indifferent until the last decades of the 20th century, when the belated winds and waves of technological modernity arrived. The central position of this modern port gives it relevant economic and political meaning, as well as its longstanding history as a maritime trade corner gives it a socio-cultural meaning. Its unique geomorphology and potential habitats (and the vicinity to important protected areas) gives it a geo-ecological meaning. Portugal, as one of the countries that ratified the European Landscape Convention (Council of Europe 2000), committed not only to identify its landscapes and to analyze their characteristics, but also to identify the forces and pressures that may impact them in order to implement strategies for landscape management, planning, and protection. Despite this, Sines landscape dynamics have not been studied yet. This particular Mediterranean coastal landscape claim for urgent analysis could contribute to its sustainable management.

In the present study we intend to investigate the history of the Sines cape landscape by the analysis and description of its dynamics over a long period of time. We made use of 2-D landscape maps built upon a patch-corridor-matrix model and historical maps as the main source of information. Our main concern was temporal changes in the composition and configuration of the elements that constitute the landscape in order to infer and understand the mechanisms behind its spatial heterogeneity. This kind of knowledge is useful for decision making related to landscape management and planning. Due to the lack of ecological based information concerning the present case landscape, we employed a rooted landscape ecological approach. In fact, although sustainable principles have been declared, the dominant tendency in modern societies is still characterized by an ecomyopia, that is, "the tendency for societies to ignore, not recognize, or fail to act on new ecological information that contradicts political arrangements, social norms or world views"' (Casagrande et al. 2017, p. 23).

The study of the landscape dynamics or its structural transformations through time supported by historical maps provided the characterization of the landscape mosaic as a whole and allowed to identify the main human drivers behind Sines cape landscape transformations over time. The landscape ecology birds-eye spatial point of view and the representation of the landscape pattern by applying the patch-corridor-matrix model allowed a broad approach to spatial phenomena and a holistic analysis of the dynamics of the study area. This could counteract with the dominant ecomyopic consensus about future developments, bearing in mind that the patch-corridor-matrix model has been considered a spatial language enhancing communication among several disciplines and decision makers (Forman 1995a). Eventually, it could even raise awareness amongst a broader public. Present results showed that today's landscape of Sines is highly disturbed and fragmented, mainly as a result of vast land use transformations. These changes intensified during the last 40 years and a very low possibility of inversion is expected. The 20th century industrial culture is the main driving force behind it. Providing a contribution to the history of the cultural coastal Mediterranean landscapes, it is desirable that the present study may support decision making in sustainable management of this territory. 


\section{Material and Methods}

\subsection{Study Area}

The study area corresponded to about 4500 hectares and consists of the territory surrounding the Sines cape. The clima is typically Mediterranean (Csa in the Köppen climate classification) in spite of Sines location at the Atlantic Portuguese coast (at $37^{\circ} 57^{\prime} \mathrm{N}$ and $08^{\circ} 52^{\prime} \mathrm{W}$, to about $150 \mathrm{~km}$ south of Lisbon). Lithology shows a mastery of Pliocene to Holocene sand and gravel formations deposited over older bedrock from Mesozoic to Paleozoic (Figure 1). There is an intrusive sub-volcanic complex underlying the quaternary sand dunes sedimentary cover. This exotic geologic feature is extended for several kilometers into the continental shelf (Pombo et al. 2004). The altitude goes from 0 (sea level) to $103 \mathrm{~m}$ above sea level, and therefore, the area is mostly a coastal plain. Being part of a landscape subunit-the extended coastal landscape known as "pine forest of littoral Alentejo" (Abreu et al. 2004) - it is characterized by the strong presence of the Atlantic Ocean and it is also under the influence of a mountain range that forms a barrier parallel to the coastal line (the Serra de Grândola, covered by dense Mediterranean vegetation of Quercus suber and Quercus rotundifolia woods). The influence of the Atlantic Ocean and the sandy soils gives rise to a natural domain, the dune fields surrounding Sines. The natural vegetation of the sedimentary cover fields comprises Mediterranean dune shrub communities belonging to the following associations: Loto-Ammophiletum, Artemisio crithmifoliae-Armerietum pungentis, Rubio-Coremetum albi and Osyrio-Juniperetum turbinatae (Pinto-Gomes and Lazare 2002). Among dune plants, species such as Armeria pungens, Artemisia crithmifolia, Corema album, and Juniperus turbinate can be found in the area. This littoral ecosystem is a natural habitat for mammals such as the wild cat (Felis silvestris), the common genet (Genetta genetta) and even the otter (Lutra lutra). Amphibians, reptiles, and birds, such as the kentish plover (Charadrius alexandrinus), can also be found. Not far north from Sines, wetlands such as Santo André e Sancha Lagoons Natural Reserve are also elements of great singularity and important biotopes for the fauna and floristic diversity of this coastal strip (Abreu et al. 2004). The southern limit of the study area marks the beginning of another important protected area, the Southwest Alentejo and Vicentine Coast Natural Park, concerning biodiversity conservation.

Sines has a long history of human presence and its archaeological heritage shows a permanent human occupation from the Paleolithic to the present date. Protected by a bay, the beach in front of the village always acted as a natural shelter for boats (Loureiro 1909). Romans used Sines as a port and industrial complex (the ruins of a fish salting factory highlight the connection between ancient people and the sea resources) and Visigoth archaeological remains indicate the continuity of human presence in later historical periods (7th century) (Pereira and Patrício 2017). Moorish domination ended in the 13th century and after the Christian conquest (Carvalho n.d.), Sines gained particular importance for trading purposes due to its strategic location, especially for the export of the regional goods. In 1362, a defensive wall was built in Sines in order to ensure the necessary security for the installation of a port-based settlement. It attests the growing strategic and commercial importance of the village (Pereira and Patrício 2017). Protected from pirates by a fortress, with its castle being built in the middle of the 15th century, the village of Sines observed a relevant population growth associated with their commercial wealth between the 16th and the 17th centuries (Quaresma 1998). The existence of vineyard, legume gardens, and windmills around the village were documented since the 16th century (Quaresma 2012). The coastal area of Sines was the subject of ancient cartographic representations, ultimately because of its nature as a maritime border but also related to specific military issues (Quaresma 2011). An old map, dated from the end of the 18th century, roughly illustrates the settlement and the ancient cultivated surroundings of Sines-Figure 2. 


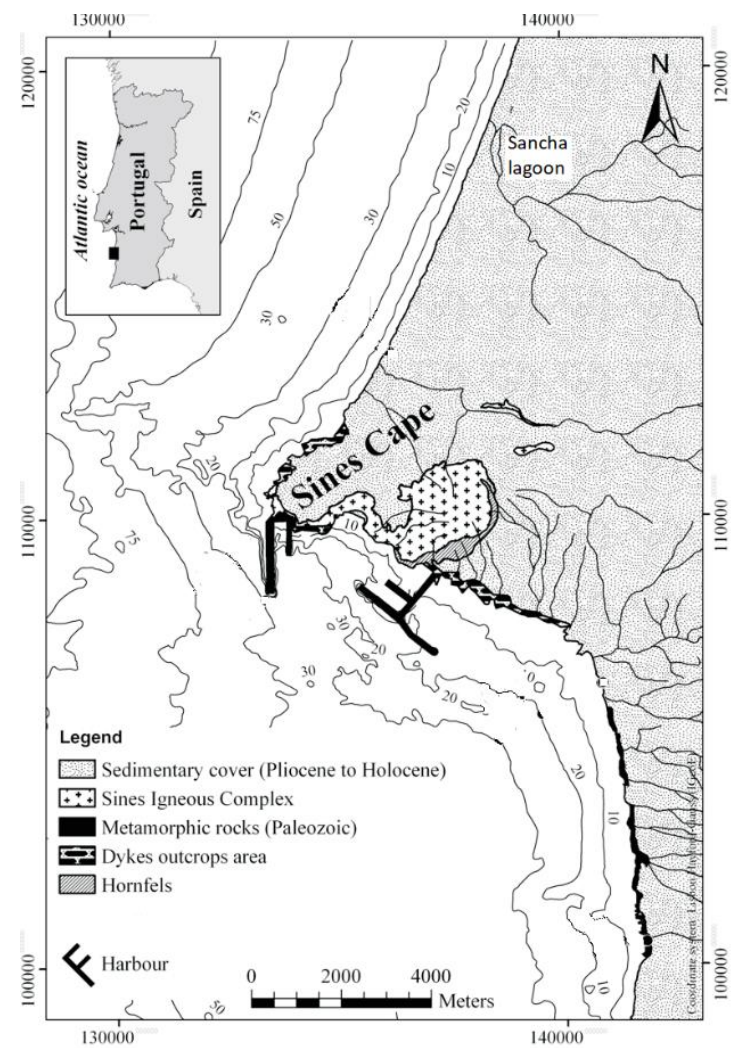

Figure 1. Geologic setting of the Sines complex (adapted from Pombo et al. 2004).

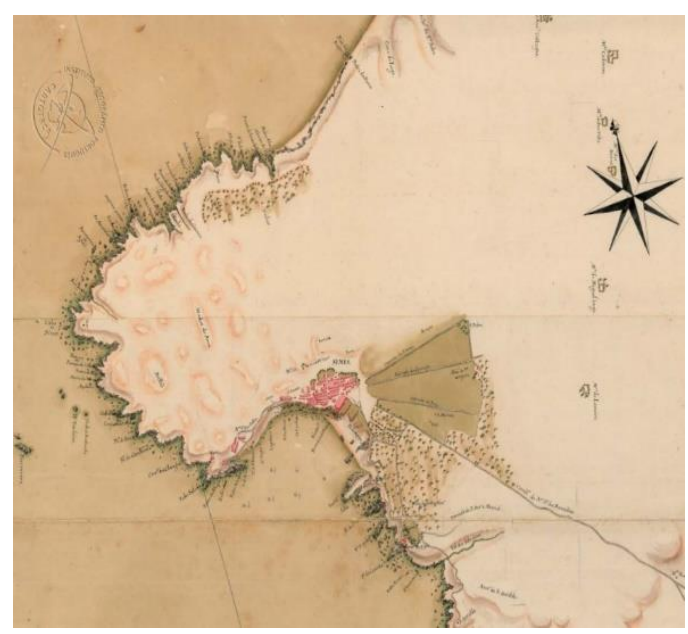

Figure 2. Sines coast map from the ending of the 18th century (extract of the Carta da Costa do Governo de Sines de 1781/1790; Chermont and Mota 1790).

During the 19th century, Sines' population increased (Quaresma 1998). The growth of the urban mesh was slow until the 1850s (Patrício 2007). Windmills were a relevant mark of the landscape at this time (Guimarães 2006). During the first half of the 20th century, Sines' surroundings were impacted by the expansion of cereal crops and forestry. It was followed by the intensification of agricultural practices and the loss of the traditional rural character. In 1970, the Portuguese national government chose Sines for the implementation of large maritime port, an associated industrial center and corresponding sea and land transport interfaces. The biggest Portuguese port complex started to be built in 1973 (APS 2004). The port started its activity in 1978 and the petrochemical terminal in 1981 (APS 2004, 2017). Major transformation of community lifestyle, economic activity, and landscape character happened as consequence. 


\subsection{Landscape Mosaic Mapping Procedure}

Our analysis of the dynamic of the Sines landscape consisted of the production of a time series of thematic maps-landscape categorical pattern maps systematically using the patch-corridor-matrix model (Forman 1995a) - covering a period of more than 120 years. The research was carried out during 2019 and 2020. The first step consisted of the production of categorical pattern maps. This task was undertaken by gathering historical maps and updated spatial information from Portuguese national libraries and national cartographic services. After a first analysis of the available information, source materials were selected to be used in the further procedures. Using digital mapping tools (AutoCad Map, version 2014), pattern maps were obtained from the digitalization and geo-referencing of source maps. Interpretation, classification, and vectorization of the perceived mosaic elements followed. The thematic pattern maps allowed an estimation of landscape metrics in a second step. To represent the landscape as a mosaic of discrete patches, the vectorized elements were classified into the following categories of patches (polygons) and corridors (lines) (Forman 1995b; Forman and Godron 1981; Forman and Godron 1986):

(1) Environmental resource patches, here designated as natural patches, are habitat areas, relatively permanent and discrete areas reflecting the normal heterogeneity of the environment-in this case, dune systems, sandy beaches, coastal cliffs, and coastal lagoons.

(2) Introduced patches are those areas dominated by an aggregation of individuals or materials introduced into a habitat matrix by human activities. They will last as long as the human management regimes maintains them. There are two main types of introduced patches: constructed or built-up land patches and planted patches. In the present case we identified built patches as isolated houses and other buildings, the urban area considered as a whole (urban buildings, roads, and other built facilities) and the industrial-port infrastructures. As planted patches we considered every type of agricultural land (orchards, vineyards, legume gardens, rice fields, cereal crops) and forested land (pine and eucalyptus plantations).

(3) Disturbance patches result from a short-term or long-term disturbance regime on a spot area in the matrix. In the present study, two types of land uses were classified as chronic disturbance patches: the natural areas managed as pasture for cattle grazing (low intensity chronic disturbance) and areas used as quarries (high intensity chronic disturbance).

(4) Remnant patches are areas that escape disturbance and persist, representing the earlier span of a certain habitat. In the present case, after the introduction of widespread disturbance in the matrix of the dune system by human activities such as agriculture, forestry, and industrial infrastructure, small patches of the previous matrix are therefore considered remnant patches.

(5) Built corridors, such as roads, highways, railways, and pipelines. The majority are narrow, such as roads, and some of the modern ones are large-the highways and pipelines.

To outline the history of the landscape of Sines, four moments were analyzed. Each moment was represented by a landscape mosaic map, using the following sources of spatial information:

(1) Former times: The main source of information was a historical map from the ending of the 19th century, the first agricultural and forest map made in Portugal—Carta Agrícola e Florestal de Portugal (designed as Carta de Pery), 1890-1900, sheet number 186, scale 1:50,000. This map is considered an irreplaceable geographical document for the reconstitution of pre-industrial landscapes of southern Portugal. It precedes the expansion of cereal crops during the first half of the 20th century and includes road networks from the medieval period. Hence, this pattern map represents the appearance of the landscape mosaic by the end of 19th century, although it is most probably representative of a longer period in the past. From the 16th to the 18th centuries, the coastal area of Sines was the subject of several cartographic representations (Quaresma 2011). Thus, other sources of cartographic information such as the old maps from the ending of the 18th century (extract of the Carta da Costa do Governo de Sines de 1781/1790; Chermont and Mota 1790) 
and from the 17th century (Turreano 1602; Massai 1621) were used as a complement in an attempt to represent the general configuration of the former landscape, previous to the 20th century.

(2) Mid 20th century: Two main sources were used, the 1:25,000 scale cartographic maps published in 1947 (Military map sheets number 515A, 526, and 516, Instituto Geográfico do Exército) and the agricultural and forest map published in 1960, scale 1:25,000 (Carta Agrícola e Florestal de Portugal 1960 sheets number 515A, 516, 526 and 535, Direcção-Geral dos Serviços Agrícolas). This mosaic pattern map represents the period of the 20th century covering the expansion of intensive agro-forestry and before the arrival of the industrial-port complex.

(3) Late 20th century: Two main sources were used: the 1:25,000 scale cartographic maps published in 1987 (Military maps sheets number 515A, 526, and 516, Instituto Geográfico do Exército) and the CORINE Land Cover from 1990 (European Environment Agency-Copernicus Land Monitoring Service-https://land.copernicus.eu/pan-european/corine-land-cover). The aim was to represent the landscape mosaic by the end of the 20th century, the period immediately after the implementation of the industrial-port complex.

(4) 21st century: To represent the landscape mosaic during current times, an editing format map obtained from the Municipality of Sines, recent Google Earth images, and the last version of land use and cover map (COS 2018, Carta de Uso e Ocupação do Solo para 2018, Direção-Geral do Território 2019) were used as main sources of information. Field work was conducted during 2019 for validation of the spatial model, including the confirmation of the mapped elements and its extension.

The description of the landscape dynamic was accomplished by a visual qualitative analysis of the mosaic maps integrated with quantitative analysis (patch metrics-area and number).

\section{Results}

The historical analysis of the Sines cape landscape reveals a dynamic in which the mosaic underwent great transformations during the 20th century and strongly intensified after the 1980s. The cape area is naturally shaped by ocean waves and winds. The overwhelming ocean was the factor behind the settlement of human communities in this maritime trade corner and its cultural character is carved in the landscape since former times. At the end of 19th century, the matrix (natural habitats) of the coastal landscape of Sines was already fragmented and disturbed by human uses, although natural systems still dominated. During the 20th century the landscape underwent major disturbances, due to the expansion of intensive agriculture and forestry and the implementation of an industrial port. Since the end of the 19th century the total area covered by introduced patches doubled, and the dune character of the former landscape is presently reduced to a few small remnant patches. The level of intervention in the landscape increased, first gradually, then abruptly. The industrial-port patches and their associated landscape corridors (roads, railways, pipelines) make the modern cultivated and forested landscape matrix a highly fragmented one, associated with lower biological diversity and lesser ecological processes (Figure 3 and Table 1).

At former times, at least from the 16th to the end of the 19th century, signs of human presence consisted of one village, a small urban patch with a couple of hectares. In the fields around it, cultivated areas and natural pastures where a few dispersed rural houses and windmills could be seen. At the time, spatial arrangements of the landscape elements defined a roughly concentric pattern-the urban area located in the coast surrounded by a large fringe of planted areas (dominated by cereal fields, with orchards, vineyards, legume garden, rice fields and pine woods covering $38 \%$ of the total area), which was surrounded by vast dune fields. The natural dune fields, a habitat matrix, covered about $60 \%$ of the study area and was partly disturbed by extensive cattle grazing ( $27 \%$ of the matrix area). Being managed as pastures, these dune patches were subjected to a chronic disturbance regime and became natural habitat at a non-climax stage. Due to the traditional Mediterranean agriculture practices of a typical mixture of cultures in dispersed parcels, the number of total patches was relatively high-Figure $3 \mathrm{~A}$ and Table 1 . Besides the relatively high level of connectivity of the dune matrix and 
the sustainability of the traditional land management practices, fragmentation associated to introduced patches and main roads interfered with the ecological flux of species in the landscape since early times.

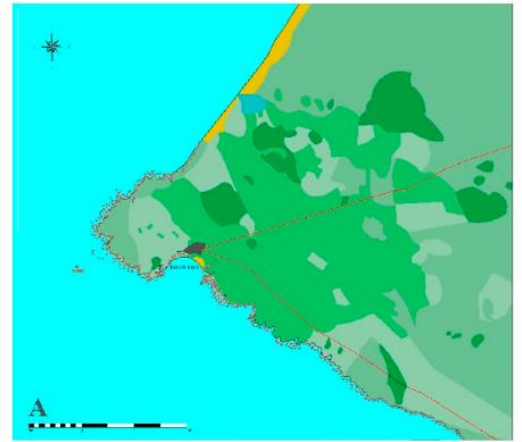

\section{NATURAL PATCHES}

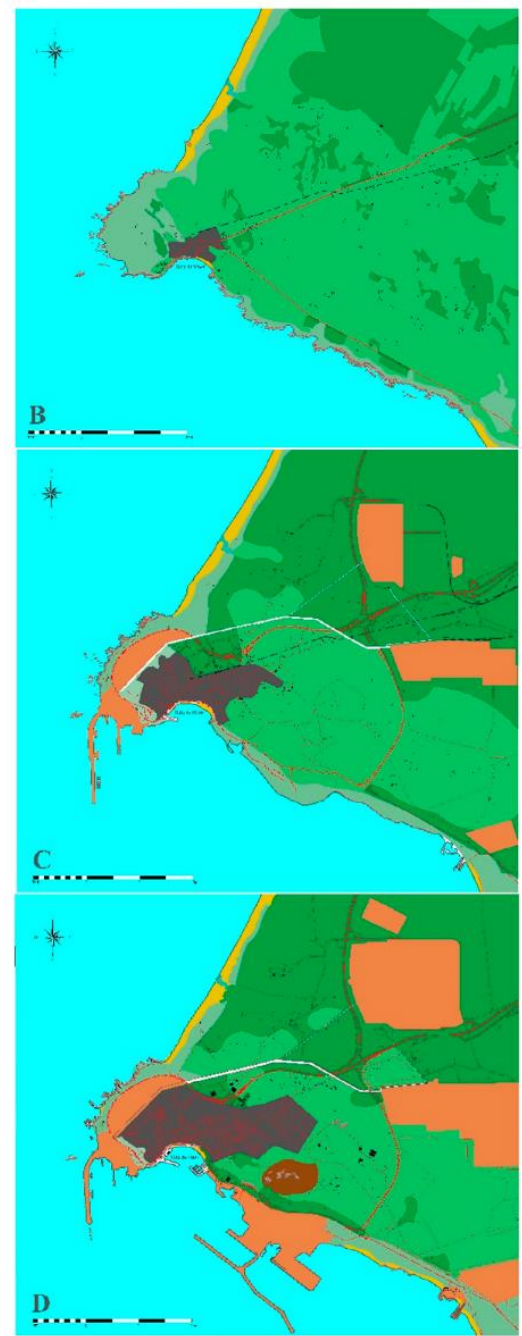

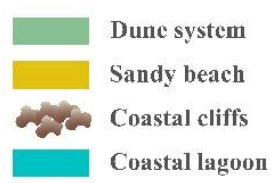

DISTURBANCE PATCHES

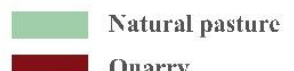

INTRODUCED PATCHES BLTLT PATCHES

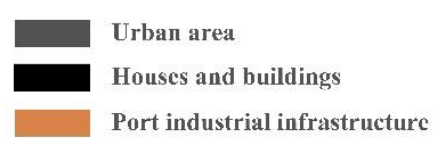

PLANTED PATCHES

Agricultural fields

Pine and Eucalyptus woods

INTRODUCED CORRIDORS

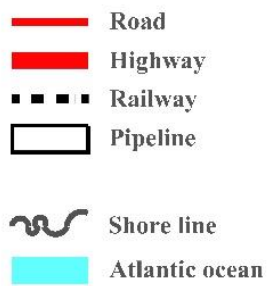

Figure 3. Sines cape landscape mosaic dynamic from former to current times: (A) -Former times (main source of information: 1890-1900 agricultural and forest historical map-Carta de Pery); (B)—Mid 20th century (main source of information: 1947 military maps and 1960 Agricultural and forest maps); (C) - End of 20th century (main source of information: 1987 military maps and 1990 CORINE land cover); (D) - Present time (main source of information: current digital maps, 2018 COS and Google Earth). 
Table 1. Sines cape landscape mosaic change: patches total area $\left(\mathrm{km}^{2}\right)$ and proportion of the study area (\%) over time.

\begin{tabular}{|c|c|c|c|c|c|c|c|c|}
\hline \multirow{3}{*}{ Patches Classes and Types } & \multirow{2}{*}{\multicolumn{2}{|c|}{$\begin{array}{c}\text { Former Times } \\
\text { Area }\end{array}$}} & \multirow{2}{*}{\multicolumn{2}{|c|}{$\frac{\text { Mid 20th Century }}{\text { Area }}$}} & \multirow{2}{*}{\multicolumn{2}{|c|}{$\begin{array}{c}\text { Late 20th Century } \\
\text { Area }\end{array}$}} & \multirow{2}{*}{\multicolumn{2}{|c|}{$\frac{\text { 21st Century }}{\text { Area }}$}} \\
\hline & & & & & & & & \\
\hline & $\mathrm{km}^{2}$ & $\%$ & $\mathrm{~km}^{2}$ & $\%$ & $\mathrm{~km}^{2}$ & $\%$ & $\mathrm{~km}^{2}$ & $\%$ \\
\hline 1. Natural Patches & 21.4 & 45.9 & 5.5 & 12.3 & 4.2 & 9.1 & 3.8 & 8.3 \\
\hline 1.1 Dune system & 20.0 & 42.9 & 4.1 & 9.0 & 3.3 & 7.1 & 2.7 & 5.9 \\
\hline 1.2 Sandy beach & 0.6 & 1.3 & 0.8 & 1.9 & 0.7 & 1.5 & 0.8 & 1.9 \\
\hline 1.3 Coastal cliffs & 0.6 & 1.3 & 0.6 & 1.3 & 0.2 & 0.4 & 0.2 & 0.4 \\
\hline 1.4. Coastal lagoon & 0.1 & 0.4 & 0.03 & 0.1 & 0.03 & 0.1 & 0.03 & 0.1 \\
\hline 2. Introduced Patches & 17.9 & 38.4 & 39.7 & 87.7 & 42.1 & 90.9 & 42.6 & 90.4 \\
\hline 2.1 Built Patches & 0.07 & 0.2 & 0.6 & 1.3 & 6.6 & 14.1 & 14.1 & 30.4 \\
\hline 2.1.1 Urban area \& houses & 0.07 & 0.2 & 0.6 & 1.3 & 2.2 & 4.7 & 4.1 & 8.9 \\
\hline 2.1.2 Industrial complex & 0 & 0 & 0 & 0 & 4.4 & 9.4 & 10.0 & 21.5 \\
\hline 2.2 Planted Patches & 17.8 & 38.2 & 39.1 & 86.4 & 35.5 & 76.8 & 28.5 & 60.0 \\
\hline 2.2.1 Agricultural fields & 14.5 & 31.2 & 28.4 & 62.7 & 14.6 & 31.5 & 12.5 & 26.5 \\
\hline 2.2.2 Forested land & 3.3 & 7.0 & 10.7 & 23.7 & 20.9 & 45.3 & 16.0 & 33.5 \\
\hline 3. Disturbance Patches & 7.3 & 15.7 & 0 & 0 & 0 & 0 & 0.5 & 1.3 \\
\hline 3.1 Quarry & 0 & 0 & 0 & 0 & 0 & 0 & 0.5 & 1.3 \\
\hline 3.2 Natural pasture (dune) & 7.3 & 15.7 & 0 & 0 & 0 & 0 & 0 & 0 \\
\hline
\end{tabular}

The territorial expansion of cereal crops and forestry that characterized Portuguese land management orientations during the first half of the 20th century, and the population growth, strongly impacted the appearance of the Sines landscape. By the middle of the 20th century, the general mosaic configuration still described a roughly concentric pattern - the urban area (which increased about ten times since the beginning of the century) surrounded by a larger fringe of agricultural fields. Replaced by cultivated and forested areas, the dune habitat was reduced to a few remnant patches (corresponding to $9 \%$ of the area). Human-related patches lost their natural former involvement as human intervention spread all over. Planted areas dominated ( $86 \%$ of the study area) creating a new landscape matrix at the time: large areas of agricultural fields (mainly cereal crops) surrounded by pine woods with hundreds of rural houses spreading over. That is, few non-habitat large patches dominated the landscape, surrounded by forested patches (pine woods that should be considered as habitat patches; very few small parcels of eucalyptus). As the total number of patches decreased, the landscape became less heterogeneous and the mosaic lost complexity. Traditional agriculture and pasture were replaced by intensive land management practices that expanded throughout the landscape-Figure 3B and Table 1. Landscape disturbance increased during the first half of the 20th century, having a relevant impact on local species response and on the flux of species through the landscape and other ecological processes.

Following the implementation of the industrial complex, the landscape mosaic denoted a second and great transformation. On one hand, at the end of the 20th century, forested areas dominated the landscape but, due to the expansion of exotic species, this forested matrix became a mosaic of habitat (Pinus woods) and non-habitat patches (Eucalyptus woods and other exotic species). On another hand, the spread of industrial patches (representing $10 \%$ of the total study area) and other associated linear structures apparently added some heterogeneity to the modern mosaic. The built area expanded (10 times in about three decades). New roads and highways, railways, and pipelines (built corridors) crossed the landscape, emerging as the new remarkable signs of the landscape. Natural habitat, dune system, sandy beaches, and rocky cliffs diminished in area and number, giving way to port structures (Figure 3C, Table 1). In this increasingly artificial landscape, the rise of landscape disturbance and fragmentation, due to the dispersal of industrial structures over the entire landscape, had a very relevant impact on local biodiversity and on the flux of species through the landscape and other ecological processes.

From the end of the 20th century onwards, the main recent landscape stressors stay active. Consequently, the constructed patches (urban and industrial-port areas) increased again in number 
and extension (covering now 30\% of the total area). The dune system and other natural habitat patches once again decreased in area. The current landscape matrix remains a cultivated and forested one, although increasingly fragmented by the new industrial patches and linear structures. The new wave of agricultural expansion is associated with a loss of forest-habitat patches-Figure 3D and Table 1. The rural (cultivated and forested) character of the landscape is now diluted by the overwhelming industrial structures. The waves of modernity that brought a new port to Sines by the end of the 20th century continue to introduce new brush strokes into this old maritime corner scenery. The fishing port, an important structure that relate to the traditional character and to the identity of Sines as a place, is now hidden by the barriers of the industrial complex and away from the community daily life.

\section{Discussion}

The Sines cape is a peculiar place in terms of natural and human-induced (cultural) characters. As expected, the production and analysis of a long-term series of landscape categorical map patterns proved to be an efficient tool to obtain insights about the unique history of the landscape, mainly for the analysis of fragmentation and its impact on landscape processes and functions. This study of landscape dynamics provided the characterization of the local landscape as a whole relying on historical maps, as they provided important historical information concerning landscape change. Historical maps have been used before for landscape reconstruction purposes (e.g., Mojses and Petrovič 2013; Stäuble et al. 2008; Petrie et al. 2019; Walz 2008). In the present case, they allowed the representation of the Sines cape landscape mosaic at different periods of history and the identification of the main human drivers behind transformations over time. The patch-corridor-matrix model proved to be a useful tool to describe the landscape pattern and its transformation through a considerable long period. Since this model has been considered a spatial language that enhances communication among several disciplines and decision makers (Forman 1995a), present results contribute to counteract the dominant ecomyopia referred by Casagrande et al. (2017). In that sense, the current application of the patch-mosaic concept may have important implications for sustainable landscape planning and management, as argued by Lovell and Johnston (2009).

Two major limitations of this approach should be referred: the source of information, i.e., historical maps, and the necessary visual interpretation to allocate delineated elements into the categorical pattern framework used for mosaic thematic mapping (categories of discrete patches). Maps are static by nature and the use of historical maps as a main source of information for the analysis of changes in the landscape has to be undertaken with awareness of survey limitations (Stäuble et al. 2008). The geometrical accuracy of the historical map used in this study provided a suitable cartographic base for the present analysis. The main challenge was the process of classifying and delineating mosaic elements (polygons) through the visual interpretation of "data" (historical maps) to derive a categorical or thematic mosaics map (categories of discrete patches) under the patch-corridor-matrix model. Much like someone turning a kaleidoscope to see different patterns (Forman 1995a), looking at the landscape as a patchwork mantle composed by different spatial elements in specific spatial arrangements and times allows a coherent look into the history of this place. Even though this approach dichotomized the landscape into generically defined habitat and non-habitat (Brudvig et al. 2017) and since the source maps (thematic agricultural maps) were made under a very different paradigm, interpretation and subsequent categorization should be considered a source of imprecision. In Linstädter's (2009) opinion, the patch-corridor-matrix model is particularly useful to classify fragmented cultural landscapes. However, in certain landscapes, delineating patches for classification and mapping purposes is currently more a matter of interpretation than following rules as defined in the patch-corridor-matrix model (Doorn and Correia 2007). Such is the case of the agro-silvo-pastoral Mediterranean landscapes in the Iberian Peninsula in which the risk of imprecision in correspondent land cover maps is high (Doorn and Correia 2007). Land cover changes in the Alentejo region originated mostly at a local scale (Doorn 2006), therefore, the present study relied on a fine scale. It is often suggested that, during the early Holocene and especially from the Roman to the Medieval periods, the human impact on the land as a consequence of clearing practices for 
agriculture and pasture represented an important factor in the widespread of mosaic landscapes in the Mediterranean coastal plains (Bellini et al. 2008). Historical evidence showed that, at least from Roman occupation to modern times, agricultural and pasture management practices gradually impacted the coastal landscape in the vicinity of the village. The semi-intensive character of the Mediterranean traditional agro-pastoral practices introduced specific challenges during the process of interpretation of historical maps and the categorization of perceived landscape elements (an example is natural pastures, a long-term, low-intensity, human-induced disturbances on natural ecosystems that colored the mosaic of Mediterranean landscapes keeping the ecosystem at non-climax stages). Following the suggestion of Bürgi and Russell (2001) that integrating the perspectives of a landscape ecologist and a historian could be important to address landscape changes, we made use of other historical sources of information (different historical maps, historical studies, paintings, and photos) as an attempt to validate the representations of past landscape mosaics.

In many European landscapes as in the rest of the world, changes usually occur in a gradual manner, making their cumulative effects more difficult to observe and are hardly perceived as great changes. Therefore, the associated cumulative impacts are underestimated (Jaeger et al. 2011). Present results emphasized both cumulative/gradual and abrupt changes that occurred in the Sines landscape during the 20th century. At former times, Sines' surroundings were already a cultural coastal landscape-agricultural fields and pastures involved by dune fields and other coastal habitats. Therefore, traditional pre-industrial agriculture and cattle grazing could be considered the main forces behind the mosaic pattern of Sines' surroundings over the centuries. Since agricultural fields were characterized by a complex mosaic of different cultures (irrigated and non-irrigated, fruits, legumes, cereals), crop rotation and long fallow periods, Mediterranean traditional agricultural and pasture management practices had a relatively low impact on local biodiversity. Agriculture was also the driver of structural changes that occurred during the first half of the 20th century, including cereal crops expansion and the progressive mechanization of agriculture. It had an impact in landscape fragmentation. The intensification of agricultural practices additionally impacted the biodiversity and the flux of species through the landscape. Those changes and impacts related to agriculture and forestry could be considered gradual cumulative changes. Instead, the abrupt changes that stressed the study area introduced a break in the relationship between society and its landscape after the 1970s. The impetuous winds of modernity have weaved new striking patches in the spatial pattern, granting it a very new character.

The accumulation of minor changes can lead to significant shifts in the landscape structure, affecting abiotic and biotic functions (Walz 2008). In the case of Sines, the expansion of agriculture and forestry during the first half of the 20th century was the first relevant alteration of the landscape structure. The dune system, a former natural habitat matrix, is currently reduced to a memory of the past, with a few remnant patches pushed away to the edge of the ocean cliffs, as a kind of anamnesis or symbolic idea lost to the sea. When landscape fragmentation increases habitat loss and isolation, vegetated areas are the only structures that serve major ecological roles and provide several benefits in a landscape (Forman 1995a). Special attention should be given to the agricultural and forested matrix for conservation biology. Traditional pastoral and agro-forestry landscapes provide a high degree of multi-functionality. Although the non-habitat matrix allowed less connectivity, as Sines landscape fragmentation rises over time, the matrix continues to be a multifunctional and vegetated one. In fact, pine woods should be considered as habitat patches. The impact of the introduction of the industrial-port structures seemed more relevant for biodiversity than the impact of modern intensive agriculture, because they offer important barriers that impose a resistance to the movement of species, energy, and materials over the landscape.

Changes in the cultural identity and threats to regional biodiversity and ecosystem services are the main cumulative impacts that could result from the transformation of the Sines cape landscape over the last century, with very low possibilities of inversion. Mediterranean cultural landscapes are characterized by highly diversified land-use patterns and agroforestry practices (Cullotta and 
Barbera 2011). This Mediterranean coastal landscape exhibits a peculiar and rich geophysical and biological environment combined with particular historical and cultural processes. The very low human intervention in the traditional Mediterranean pastoral systems emphasizes the assumed importance of the dune system as a whole (managed and non-managed natural fields) until the beginning of the 20th century. The former natural habitats were significant elements for local biodiversity and played an important role in the regional flux of species, through the entire coastal landscape. Forestry and agriculture expansion during the 20th century affected local and regional ecological processes. In addition, the spatial discontinuity of natural habitats (and fragmentation of forested patches) imposed in the Sines cape since the last 40 years resulted in an effective barrier to the natural movement of species. Within the current extended "pine forest of littoral Alentejo" landscape sub-unit (Abreu et al. 2004), the Sines cape landscape stretch represents a break instead of a bridge between important nature conservation areas (the coastal natural park and the coastal lagoons natural reserve). This makes the present level of disturbance and fragmentation of the local landscape of upmost importance. Today's intensive use of the study area by industrial structures means that economic interests have overlapped nature and biodiversity conservation values. At the local level, planning and design of green infrastructures by the Municipality of Sines will have important implications for their landscape functioning. Such protective subsystems need to be placed in a broader scale for a better understanding of the connections of their several components and must be related with production and governance, especially in a regional scale where the decision making can be more powerful.

The ocean is the major factor for the development of Sines, a maritime trade corner since Roman times. From the 1980s onwards, the close connection between the port (and the waterfront) and the city became detrimental. More than the trends of separation between ports and cities fading its direct relationship (Veenboer 2014), the enormous wave of modernity reached the Sines landscape with an imposing industrial crude processing complex that overlapped the preexistent fishing port. The strong relation of the Sines population with the waterfront decreased and their traditional identity was lost (Norcliffe et al. 1996). Since the very new "hard" pieces have been added to this kaleidoscope, as it goes round and round, further and further, it separates the port and the town as an invisible but clear barrier imposed between the city and coastline. Metaphorically speaking, since the giant of modernity sat on the tip of the Sines cape and built factories, chimneys, pipes, and other heavy industrial structures, he isolated the village from the sea and broke the flow of waves that kept the village alive. The reconnection of Sines inhabitants with their waterfront is a crucial issue.

Sines landscape is representative of the variability of coastal cultural Mediterranean landscapes; thereby the present study provides a contribution to the history of the cultural coastal Portuguese and Mediterranean landscapes, besides the provision of knowledge about the local landscape. Regular analysis of the Sines landscape mosaic is needed to capture the continuous pattern change in such a unique and under-pressure landscape. Landscape pattern analysis is an active research field. Following this attempt to approach the Sines landscape dynamics and while novel tools and insights emerge, further developments for the present case study are expected. Topics related with measuring patterns, such as identifying hotspots for conservation and informed conservation strategies (Costanza et al. 2019), or other processes outcomes (e.g., ecosystem services), including a broader regional context, will contribute to a better understanding of landscape connectivity and habitat fragmentation. These aspects are crucial in the context of landscape sustainable management.

\section{Conclusions}

The Sines cape is naturally shaped by ocean waves and winds and the overwhelming ocean is also the factor behind human communities from this old maritime trade corner since former times carved the landscape with its cultural character. Dominated by port-related activities, over centuries the landscape of Sines looked like a traditional cultural Mediterranean coastal landscape. Present results emphasized the recent abrupt transformation that occurred in this landscape mediated by industrial 
forces and modern human waves that reached this western European coastal corner about 40 years ago. Today's landscape of Sines is highly disturbed and fragmented, with very low possibilities of inversion.

The study of the present case landscape dynamics allowed us to identify the main human drivers behind Sines cape's surrounding transformations over time. Historical maps provided a representation of landscape mosaics from the past when the patch-corridor-matrix model was applied, which allowed the landscape change analysis over a long period of time. The history of such a unique landscape, such a peculiar and rich geophysical and biological environment combined with particular historical and cultural processes, part of the variability of the Mediterranean cultural landscapes, approached by such specific spatial vocabulary, provided a contribution towards the knowledge of cultural coastal Mediterranean landscapes and should be helpful in the support of decision making concerning sustainable management of this territory.

Author Contributions: Conceptualization, J.F. and C.B.S.; methodology, J.F. and N.d.S.L.; validation, J.B. and C.B.S.; formal analysis, J.F. and C.B.S.; investigation, J.F. and J.B.; resources, J.B.; data curation, J.B.; writing-original draft preparation, J.F. and C.B.S.; writing—review and editing, N.d.S.L.; visualization, J.B.; supervision, J.F. All authors have read and agreed to the published version of the manuscript.

Funding: This research received no external funding.

Conflicts of Interest: The authors declare no conflict of interest.

\section{References}

Abreu, Alexandre C., Teresa P. Correia, and Rosário Oliveira. 2004. Contributos para a Identificação e Caracterização da Paisagem em Portugal Continental. Lisboa: DGOTDU, ISBN 972-8569-28-9.

Aminzadeh, Behnaz, and Mahdi Khansefid. 2010. A case study of urban ecological networks and a sustainable city: Tehran's metropolitan area. Urban Ecosystems 13: 23-36. [CrossRef]

Antrop, Marc. 2000. Geography and Landscape Science. In Belgeo [Online], 1-2-3-4|2000, Online Since 12 July 2015 , Connection on 30 April 2019. Available online: http://journals.openedition.org/belgeo/13975 (accessed on 30 April 2019).

APS (Administração do Porto de Sines). 2004. Porto de Sines—25 Anos. Sines: Edição Administração do Porto de Sines, S.A.

APS (Administração do Porto de Sines). 2017. Porto de Sines, 40 Anos, 40 Imagens. Sines: Edição Administração dos Portos de Sines e do Algarve, S.A.

Bellini, Cristina, Marta Mariotti-Lippi, and Carlo Montanari. 2008. The Holocene landscape history of the NW Italian coasts. The Holocene 19: 1161-72. [CrossRef]

Brudvig, Lars A., Shawn J. Leroux, Cécile H. Albert, Emilio M. Bruna, Kendi F. Davies, Robert M. Ewers, Douglas J. Levey, Renata Pardini, and Julian Resasco. 2017. Evaluating conceptual models of landscape change. Ecography 40: 74-84. [CrossRef]

Bürgi, Matthias, and Emily W. B. Russell. 2001. Integrative methods to study landscape changes. Land Use Policy 18: 9-16. [CrossRef]

Bürgi, Matthias, Angela Straub, Urs Gimmi, and Daniel Salzmann. 2010. The recent landscape history of Limpach valley, Switzerland: Considering three empirical hypotheses on driving forces of landscape change. Landscape Ecology 25: 287-97. [CrossRef]

Carvalho, A. F. T. n.d. Porto de Sines, Porta Atlântica da Europa. Sines: Edição Administração do Porto de Sines, S.A.

Casagrande, David G., E. C. Jones, F. S. Wyndham, J. R. Stepp, and R. Zarger. 2017. Ecomyopia in the Anthropocene. Anthropology Today 33: 23-25. [CrossRef]

Chermont, João Gabriel, and Diogo Correia da Mota. 1790. Carta da Costa do Governo de Sines. Lisboa: Instituto Geográfico Português, CA 282.

Costanza, J. K., K. Riitters, P. Vogt, and J. Wickham. 2019. Describing and analyzing landscape patterns: Where are we now, and where are we going? Landscape Ecology 34: 2049-55. [CrossRef]

Council of Europe. 2000. European Landscape Convention. CETS No. 176. Strasbourg: Council of Europe.

Cullinan, Valerie I., and John M. Thomas. 1992. A comparison of quantitative methods for examining landscape pattern and scale. Landscape Ecology 7: 211-27. [CrossRef] 
Cullotta, Sebastiano, and Giuseppe Barbera. 2011. Mapping traditional cultural landscapes in the Mediterranean area using a combined multidisciplinary approach: Method and application to Mount Etna (Sicily; Italy). Landscape and Urban Planning 100: 98-108. [CrossRef]

Dominik, Christophe, Loïc Menanteau, Celine Chadenas, and Laurent Godet. 2012. The influence of salina landscape structures on terrestrial bird distribution in the Guérande basin (Northwestern France). Bird Study 59: 483-95. [CrossRef]

Domon, Gérald, and André Bouchard. 2007. The landscape history of Godmanchester (Quebec, Canada): Two centuries of shifting relationships between anthropic and biophysical factors. Landscape Ecology 22: 1201-14. [CrossRef]

Doorn, Anne M. van. 2006. Extensification trends in Mediterranean land use systems: Does the landscape homogenisation dogma apply? A landscape change study (1958-2000) in the Portuguese Alentejo. Journal of Mediterranean Ecology 7: 41-52.

Doorn, Anne M. van an, and Teresa Pinto Correia. 2007. Differences in land cover interpretation in landscapes rich in cover gradients: Reflections based on the montado of South Portugal. Agroforest System 70: 169-83. [CrossRef]

Forman, Richard T. T. 1995a. Land Mosaics: The Ecology of Landscapes and Regions. New York: Cambridge University Press.

Forman, Richard T. T. 1995b. Some general principles of landscape and regional ecology. Landscape Ecology 10: 133-42. [CrossRef]

Forman, Richard T. T., and Michel Godron. 1981. Patches and Structural Components for a Landscape Ecology. BioScience 31: 733-40.

Forman, Richard T. T., and Michel Godron. 1986. Landscape Ecology. New York: John Wiley \& Sons, p. 619+xix. ISBN 0-471-87037-4.

Guimarães, Paulo Eduardo. 2006. Elites e Indústria no Alentejo (1890-1960). Um estudo sobre o comportamento económico de grupos de elite em contexto regional no Portugal contemporâneo. Évora: Edições Colibri e CIDEHUS-EU, Estudos \& colóquios, ISBN 972-772-642-9.

Jaeger, J. A., Tomás Soukup, Luis Madriñán, Christian Schwick, and Felix Kienast. 2011. Landscape fragmentation in Europe. In European Landscape Dynamics-CORINE Land Cover Data. Copenhagen: EEA, pp. 157-98.

Jones, Michael. 2003. The concept of cultural landscape: Discourse and narratives. In Landscape Interfaces. Dordrecht: Springer, pp. 21-51.

Kracker, Laura. 1997. An approach to the quantification and classification of aquatic landscapes. Middle States Geographer 30: 19-28.

Linstädter, Anja. 2009. Landscape Ecology of Savannas. In African Landscapes. New York: Springer, pp. 79-103.

Loureiro, Adolpho. 1909. Os Portos Marítimos de Portugal. Vol IV. Lisboa: Imprensa Nacional.

Lovell, Sarah T., and Douglas M. Johnston. 2009. Designing landscapes for performance based on emerging principles in landscape ecology. Ecology and Society 141: 44. [CrossRef]

Luo, Lei Xinyuan Wang, Jie Liu, Huadong Guo, Rosa Lasaponar, Wei Ji, and Chuansheng Liu. 2017. Uncovering the ancient canal-based tuntian agricultural landscape at China's northwestern frontiers. Journal of Cultural Heritage 23: 79-88. [CrossRef]

Massai, Alexandre. 1621. Descripcão do Reino do Algarve, Descripcão Relação do Reino de Portvgal, Segvndo Tratado, 1621, fl 68, Arquivos Nacionais Torre do Tombo, Chancelarias Reais, D.Pedro I, fl.76r. Publicação Chancelarias Medievais Portuguesas. D.Pedro, p. 323, no 705.

Mojses, Matej, and František Petrovič. 2013. Land use changes of historical structures in the agricultural landscape at the local level—Hriňová case study. Ekológia (Bratislava) 32: 1-12. [CrossRef]

Norcliffe, G., Keith Bassett, and Tony Hoare. 1996. The emergence of postmodernism on the urban waterfront: Geographical perspectives on changing relationships. Journal of Transport Geography 4: 123-34. [CrossRef]

Patrício, Sandra. 2007. Trabalhar em Sines entre 1900 e 1950 (I). Sines: Arquivo Aberto Sineense.

Pereira, Paula, and Sandra Patrício. 2017. Sines, a Terra e o Mar. Sines: Edição Câmara Municipal de Sines, ISBN 978-72-8261-18-4.

Petrie, Cameron A., Hector A. Orengo, Adam S. Green, Joanna R. Walker, Arnau Garcia, Francesc Conesa, J. Robert Know, and Ravindra N. Singh. 2019. Mapping archaeology while mapping an empire: Using historical maps to reconstruct ancient settlement landscapes in modern India and Pakistan. Geosciences 9: 11. [CrossRef] 
Pinto-Gomes, Carlos J., and Jean-Jacques Lazare. 2002. La végétation du centre et sud du Portugal. Guide du voyage botanique. Journal de Botanique de la Société Botanique de France 17: 1-89.

Pombo, Joaquim, J. Carvalho, A. Rodrigues, R. Taborda, and Anabela Oliveira. 2004. The Sines Sub-Volcanic Intrusive Complex: Imprint on the Inner Shelf Sedimentary Cover (Sines, Portugal). Journal of Coastal Research 39: 250-54.

Quaresma, António M. 1998. Sines no trânsto da época medieval para a moderna. In Da Ocidental praia Lusitana-Vasco da Gama e o seu Tempo. Lisboa: Comissão Nacional dos Descobrimentos.

Quaresma, António M. 2011. Litoral alentejano: Dois séculos de cartografia (XVII e XVIII). Paper presented at IV Simpósio LusoBrasileiro de Cartografia Histórica, Porto, Portugal, November 9-12; ISBN 978-72-8932-88-6.

Quaresma, António M. 2012. Sines Medieval e Moderna, (Séculos XIV-XVIII). In O concelho de Sines da fundação à época moderna. Sines: Ed. Camara Municipal de Sines, pp. 73-124. ISBN 978-72-8261-08-5.

Ribeiro, Orlando. 1945. Portugal, o Mediterrâneo e o Atlântico: Estudo geográfico. Coimbra: Coimbra Editora Lda.

Rodrigues, Jorge Nascimento, and Tessaleno Devezas. 2009. Portugal-O Pioneiro da Globalização. A Herança das Descobertas. V.N. Famalicão: Centro Atlântico, Lda, ISBN 978-89-615-077-8.

Simensen, Trond, Rune Halvorsen, and Lars Erikstad. 2018. Methods for landscape characterisation and mapping: A systematic review. Land Use Policy 75: 557-69. [CrossRef]

Stäuble, Sabine, Simon Martin, and Emmanuel Reynard. 2008. Historical mapping for landscape reconstruction. Examples from the Canton of Valais (Switzerland). Paper presented at Mountain Mapping and Visualisation: 6th ICA Mountain Cartography Workshop, Lenk, Switzerland, February 11-15.

Taylor, Ken. 2012. Landscape and meaning: Context for a global discourse on cultural landscape values. In Managing Cultural Landscapes. Milton Park: Routledge, Taylor \& Francis Group.

Taylor, Ken, and Jane Lennon. 2011. Cultural landscapes: A bridge between culture and nature? International Journal of Heritage Studies 17: 537-54. [CrossRef]

Turreano, Leonardo. 1602. Costa e plano da villa de Sines, $C^{a}$ de 1602. Lisboa: Arquivo Nacional Torre do Tombo, códice da casa cadaval.

Uzun, Osman, and Pinar Gültekin. 2011. Process analysis in landscape planning, the example of Sakarya/Kocaali, Turkey. Scientific Research and Essays 6: 313-31.

Veenboer, D. P. 2014. The Port-City Relationship. The Success of Urban Maritime Ports. Master's thesis, Erasmus University of Rotterdam, Rotterdam, The Netherlands.

Vos, Willem, and Herman Meekes. 1999. Trends in European cultural landscape development: Perspectives for a sustainable future. Landscape and Urban Planning 46: 3-14. [CrossRef]

Walz, Ulrich. 2008. Monitoring of landscape change and functions in Saxony (Eastern Germany)—Methods and indicators. Ecological Indicators 8: 807-17. [CrossRef]

Wu, Jianguo. 2010. Landscape of culture and culture of landscape: Does landscape ecology need culture? Landscape Ecology 25: 1147-50. [CrossRef]

Wu, Zhifeng, Lezhang Wei, and Zhiqiang Lv. 2012. Landscape Pattern Metrics: An Empirical Study from 2-D to 3-D. Physical Geography 33: 383-402. [CrossRef]

Zaccarelli, Nicola, Kurt H. Riitters, Irene Petrosillo, and Giovanni Zurlini. 2008. Indicating disturbance content and context for preserved areas. Ecological Indicators 8: 841-53. [CrossRef]

Publisher's Note: MDPI stays neutral with regard to jurisdictional claims in published maps and institutional affiliations.

(C) 2020 by the authors. Licensee MDPI, Basel, Switzerland. This article is an open access article distributed under the terms and conditions of the Creative Commons Attribution (CC BY) license (http://creativecommons.org/licenses/by/4.0/). 